\title{
Níveis de Proteína Bruta em Dietas para Bovinos de Corte: Consumo e Digestibilidades Total e Parcial dos Nutrientes ${ }^{1}$
}

\author{
Maria Andréa Borges Cavalcante ${ }^{2}$, Odilon Gomes Pereira ${ }^{3}$, Sebastião de Campos Valadares \\ Filho $^{3}$, Karina Guimarães Ribeiro ${ }^{4}$, Fernanda Helena Martins Chizzotti ${ }^{5}$, Dalton Henrique Pereira ${ }^{5}$
}

\begin{abstract}
RESUMO - Avaliaram-se os consumos e as digestibilidades total e parcial dos nutrientes em novilhos Holandês x Zebu recebendo dietas contendo quatro níveis de proteína bruta (10,5; 12; 13,5 e 15\% de PB na matéria seca), constituídas de 65\% de feno de capim-tifton 85 e 35\% de concentrado. Foram utilizados quatro animais castrados, fistulados no rúmen e abomaso, com peso vivo médio inicial de $487,3 \mathrm{~kg}$, distribuídos em um quadrado latino 4 x 4. Cada período experimental teve duração de 20 dias - 10 para adaptação às dietas, seis para coletas de amostras de fezes e digestas de abomaso, um para a coleta de líquido ruminal, um para a coleta total de urina, em 24 horas, e dois para a coleta de conteúdo ruminal. Para determinação da excreção fecal, utilizou-se o óxido crômico como indicador. Os consumos de matéria seca (MS), matéria orgânica (MO), fibra em detergente neutro (FDN) e nutrientes digestíveis totais (NDT) não foram influenciados pelos níveis de proteína bruta (PB) das dietas, mas os consumos de PB aumentaram e os de extrato etéreo (EE) e carboidratos não-fibrosos (CNF) reduziram com o incremento de PB das dietas. As digestibilidades aparentes totais da MS, MO e PB aumentaram linearmente com a concentração protéica das dietas. As digestibilidades aparentes ruminal e intestinal dos nutrientes não foram afetadas pelos níveis de $\mathrm{PB}$ das dietas, com exceção à digestibilidade intestinal da PB, que aumentou 2,77 unidades para cada percentual de PB acrescentado à dieta.
\end{abstract}

Palavras-chave: fibra em detergente neutro, fibra em detergente ácido, nitrogênio insolúvel em detergente neutro, nitrogênio insolúvel em detergente ácido, carboidratos não-fibrosos, lignina

\section{Crude Protein Levels in Diets of Beef Cattle: Intake and Apparent Total Tract, Intestinal, and Ruminal Digestibilities of Nutrients}

\begin{abstract}
The objective of this trial was to study the effects of different dietary levels of crude protein (CP) on intake and apparent total tract, intestinal, and ruminal digestibilities of nutrients in Holstein x Zebu steers. The diets contained [dry matter (DM) basis]: $10.5,12,13.5$, or $15 \%$ of CP and a forage (Tifton 85 ):concentrate ratio of $65: 35$. Four castrated animals averaging $487.3 \mathrm{~kg}$ of body weight at the beginning of the trial and fitted with both abomasum and rumen cannulas were randomly assigned to a $4 \mathrm{x} 4$ Latin square. Each experimental period lasted 20 days with 10 days for diet adaptation and 10 days for sample collection (feces, abomasum digesta, ruminal content, and urine). Chromium oxide was used as the external marker for determination of fecal excretion. Increasing dietary levels of CP did not change significantly the intakes of dry matter (DM), organic matter (OM), neutral detergent fiber (NDF), and total digestible nutrients (TDN). However, intake of CP increased while that of ether extract (EE) and non-fiber carbohydrate (NFC) decreased with the increment of dietary CP. Apparent total tract digestibilities of DM, OM, and CP all increased linearly by increasing the dietary CP from 10.5 to $15 \%$. Except for intestinal digestibility of CP that increased 2.77 percentage units for each $1 \%$ increment in the diet CP, the different dietary CP levels did not affect intestinal and ruminal digestibilities of all remaining nutrients in the current trial.
\end{abstract}

Key Words: neutral detergent fiber, acid detergent fiber, neutral detergent insoluble nitrogen, acid detergent insoluble nitrogen, nonfiber carbohydrate, lignin

\section{Introdução}

O nível de produtividade de bovinos de corte depende, entre outros fatores, do potencial genético do animal e do consumo de nutrientes, que, em grande parte, é determinado pelo uso de alimentos à base de volumoso, muito importante em sistemas de alimenta- ção, por determinar o atendimento às exigências de mantença e de produção dos animais.

Em geral, o consumo é inversamente relacionado ao teor de parede celular do alimento (Mertens \& Ely, 1979) e, em muitas situações, está associado à digestibilidade da dieta (Waldo \& Jorgensen, 1981), que indica a capacidade do alimento em ser aprovei-

\footnotetext{
${ }^{1}$ Parte da tese de Doutorado da primeira autora apresentada à UFV

2 Bolsista de Desenvolvimento Científico Regional/CNPq do Depto. de Zootecnia da UFC, Depto. de Zootecnia, BI. 809, Campus do Pici, Fortaleza-CE. E.mail: andreacavalcante@bol.com.br

3 Professor do Departamento de Zootecnia da UFV, bolsista do CNPq Viçosa, MG. E.mail: odilon@mail.ufv.br

${ }^{4}$ Professora do Departamento de Zootecnia da FAFEID, Diamantina, MG. E.mail: kgr_fafeid@yahoo.com.br

5 Zootecnista, estudante de Doutorado do curso de Zootecnia da UFV, Viçosa, MG.
} 
tado pelo animal e sofre influência de fatores, como o nível de proteína bruta da dieta.

O consumo pode ser limitado pelo alimento, pelo animal ou pelas condições de alimentação. Segundo Mertens (1994), em torno de 60 a 90\% das variações no desempenho animal podem ser atribuídas às alterações no consumo de nutrientes e de 10 a $40 \%$, às mudanças na digestibilidade dos alimentos.

Os fatores físicos e fisiológicos reguladores da ingestão são alterados pelo aumento da digestibilidade da matéria seca (MS) da dieta, de modo que, para dietas de digestibilidade abaixo de $66 \%$, o consumo é praticamente determinado pelos fatores físicos (Conrad et al., 1964, citados pelo NRC, 1989). Além dos mecanismos reguladores mencionados, Mertens (1992) considera ainda o mecanismo psicogênico resposta do animal a fatores inibidores ou estimuladores relacionados ao alimento ou ao ambiente que não são ligados ao valor energético do alimento ou ao efeito de enchimento.

A proteína é o segundo nutriente mais exigido pelos ruminantes. As exigências protéicas dos ruminantes são atendidas mediante a absorção intestinal de aminoácidos provenientes, principalmente, da proteína microbiana sintetizada no rúmen e da proteína dietética não-degradada no rúmen (Valadares Filho \& Valadares, 2001).

Tanto a deficiência como o excesso de proteína na dieta podem reduzir o consumo; a deficiência, pelo nãoatendimento aos requerimentos dos microrganismos ruminais e o excesso, pela toxidez pela liberação de amônia, que aumenta o teor de uréia, via urina, constituindo em desperdício de proteína. Valadares et al. (1997b) relataram que, quando o suprimento de nitrogênio $(\mathrm{N})$, originário da proteína da dieta ou da reciclagem endógena, não atende às exigências dos microrganismos ruminais, pode ocorrer limitação do crescimento microbiano, afetando negativamente a digestibilidade da parede celular e o consumo e acarretando baixo desempenho animal. Valadares et al. (1997a), ao fornecerem dietas com diferentes teores protéicos (7; 9,5; 12 e $14,5 \%$, na MS) a novilhos zebuínos, verificaram que o nível de 7\% de PB diminuiu o consumo de MS e MO, provavelmente porque esse teor de proteína foi insuficiente para promover o crescimento microbiano adequado. O NRC (1984) recomenda teores de 12\% de PB para bovinos em terminação.

Alves (2001), ao avaliar dietas contendo diferentes concentrações protéicas (12 e 15\%) para novilhos azebuados e cruzados F1 Gir-Holandês e GuzeráHolandês nas fases de recria e terminação, constatou que os consumos de MS e de nutrientes não foram influenciados pelas dietas. Em estudo semelhante, Ítavo et al. (2002) utilizaram animais Nelore submetidos a dietas com 15 e 18\% de proteína bruta e não encontraram diferença no consumo e na digestibilidade aparente dos nutrientes.

Em estudo com novilhos Holandês, 1/2HolandêsGuzerá, $1 \frac{2}{2}$ Holandês-Gir e Zebu recebendo dietas com $60 \%$ de feno de capim-tifton 85 contendo 12 e $15 \%$ de PB, Rennó (2003) não notou diferenças no consumo de nutrientes, exceto o de PB. Apenas digestibilidades totais de PB e EE foram influenciadas pelas dietas.

Realizou-se este estudo objetivando-se avaliar os consumos e as digestibilidades totais e parciais dos nutrientes em novilhos mestiços Holandês x Zebu recebendo dietas com diferentes níveis de proteína bruta.

\section{Material e Métodos}

O experimento foi conduzido na Central de Experimentação, Pesquisa e Extensão do Triângulo Mineiro (CEPET), da Universidade Federal de Viçosa, no período de julho a outubro de 2001. A CEPET localizase no município de Capinópolis, no Pontal do Triângulo Mineiro, Minas Gerais, a 620,2 $\mathrm{m}$ de altitude, 18,41 ${ }^{\circ}$ latitude sul e $49,34^{\circ}$ longitude oeste. O clima é do tipo Aw, segundo classificação de Köppen, quente e úmido, com temperatura do mês mais frio acima de $18^{\circ} \mathrm{C}$, estação chuvosa no verão e seca no inverno e precipitações médias anuais entre 1.400 e 1.600 mm.

Foram utilizados quatro animais mestiços Holandês x Zebu, castrados, com peso vivo inicial de $487,3 \mathrm{~kg} \pm 54,5$, fistulados no rúmen e abomaso, distribuídos em um quadrado latino 4 x 4, (quatro tratamentos e quatro períodos experimentais). Os tratamentos consistiram de dietas contendo níveis crescentes de proteína bruta (10,5; 12; 13,5 e 15\% na MS total), constituídas de $65 \%$ de feno de capim-tifton 85 (Cynodon spp.) e 35\% de concentrado.

O feno foi produzido em uma área de 5 ha, estabelecida com capim-tifton 85, efetuando-se o corte com uma segadeira de barra, a aproximadamente $5 \mathrm{~cm}$ do solo, quando o capim se encontrava em avançado estádio de maturidade (florescimento pleno). O enfardamento foi realizado no início da tarde do dia seguinte ao corte, utilizando-se uma enfardadeira para fardos redondos. Antes de ser fornecido aos animais, o 
feno foi picado em uma máquina utilizada para confecção de pré-secado, com regulagem para partículas de, aproximadamente, $6 \mathrm{~mm}$ de comprimento.

As proporções dos ingredientes nas dietas e a composição bromatológica dos alimentos e das dietas encontram-se, respectivamente, nas Tabelas 1, 2 e 3.

As dietas com 10,$5 ; 12 ; 13,5$ e $15 \%$ de PB continham níveis de uréia de 0,$71 ; 0,87 ; 1,03$ e 1,19\% na MS, respectivamente, que corresponderam, nos concentrados, aos teores de 1,988; 2,436; 2,884 e 3,332\% de $\mathrm{PB}$, de modo que a relação entre o teor de PB proporcionado pelos demais ingredientes dos concentrados e da uréia foi de aproximadamente 8,79.

Os animais foram mantidos em baias individuais de $10 \mathrm{~m}^{2}$, providas de comedouros e bebedouros. A alimentação foi fornecida à vontade, duas vezes ao dia, às 7 e $15 \mathrm{~h}$, de forma a permitir 10\% de sobras.

Cada período experimental teve duração de 20 dias - 10 para adaptação às dietas, seis para coletas de amostras de fezes, digestas de abomaso, alimentos fornecidos e sobras, um para a coleta de líquido ruminal, para determinação do $\mathrm{pH}$ e da concentração de amônia ruminal, um para a coleta total de urina, em 24 horas, e dois para a coleta de conteúdo ruminal, para determinação da taxa de passagem. Os animais foram pesados ao início e ao final de cada período experimental.

Para determinação do consumo diário, durante o período de coletas, o alimento fornecido e as sobras foram diariamente pesados e amostrados. Foram elaboradas amostras compostas do feno e dos concentrados, por tratamento, e das sobras, por animal, por período, que foram devidamente armazenadas a $-15^{\circ} \mathrm{C}$. Ao final do experimento, as amostras foram pré-secas em estufas de ventilação forçada a $65^{\circ} \mathrm{C}$, processadas em moinho de facas tipo "Willey" com peneira de malha de $1 \mathrm{~mm}$ e submetidas às análises laboratoriais.

A produção de matéria seca fecal e os fluxos de MS nos compartimentos do trato gastrintestinal foram estimados com a utilização do óxido crômico como indicador, administrado em dose diária única de 15 g, via fístula ruminal, do $4^{\circ}$ ao $16^{\circ}$ dia de cada período experimental, sempre às $11 \mathrm{~h}$. As coletas de fezes e de digestas de abomaso foram feitas uma vez ao dia, em intervalos de 26 horas, iniciando-se às $8 \mathrm{~h}$ do $11^{0}$ dia e terminando às $18 \mathrm{~h}$ do $16^{0}$ dia de cada período experimental. As amostras foram armazenadas a $-15^{\circ} \mathrm{C} \mathrm{e}$, posteriormente, submetidas à pré-secagem em estufa de ventilação forçada a $65^{\circ} \mathrm{C}$, por 72 horas, e processadas em moinho com peneira de $1 \mathrm{~mm}$, elaborando-se uma amostra composta por animal, por período. As amostras compostas foram acondicionadas em recipientes de vidros e posteriormente analisadas.

As análises dos teores de matéria seca (MS), matéria orgânica (MO), compostos nitrogenados totais, fibra em detergente ácido (FDA), extrato etéreo (EE) e lignina foram realizadas conforme procedimentos descritos por Silva \& Queiroz (2002). A concentração de fibra em detergente neutro (FDN) foi determinada segundo o método da autoclave de Pell \& Schofield (1993). O teor de cromo nas fezes foi determinado pela técnica proposta por Williams et al. (1962), utilizando-se o espectrofotômetro de absorção atômica.

Tabela 1 - Proporções dos ingredientes nas dietas, expressas na matéria seca (\%), de acordo com os níveis de proteína bruta

Table 1 - Ingredient composition of diets with different crude protein level on dry matter basis (\%)

\begin{tabular}{|c|c|c|c|c|}
\hline \multirow[t]{2}{*}{$\begin{array}{l}\text { Ingrediente } \\
\text { Ingredient }\end{array}$} & \multicolumn{4}{|c|}{$\begin{array}{c}\text { Nível de PB (\%) } \\
\text { CP level (\%) }\end{array}$} \\
\hline & 10,5 & 12 & 13,5 & 15 \\
\hline Feno de capim-tifton 85 (Bermudagrass hay) & 65,00 & 65,00 & 65,00 & 65,00 \\
\hline Fubá de milho (Ground corn) & 28,37 & 25,11 & 21,84 & 18,82 \\
\hline Farelo de algodão (Cottonseed meal) & 5,14 & 8,22 & 11,31 & 14,16 \\
\hline Uréia (Urea) & 0,71 & 0,87 & 1,03 & 1,19 \\
\hline Sulfato de amônia (Ammonium sulfate) & 0,08 & 0,10 & 0,12 & 0,13 \\
\hline Cloreto de sódio (Sodium chloride) & 0,31 & 0,31 & 0,31 & 0,31 \\
\hline Fosfato bicálcico (Dicalcium phosphate) & 0,28 & 0,28 & 0,28 & 0,28 \\
\hline Calcáreo calcítico (Limestone) & 0,08 & 0,08 & 0,08 & 0,08 \\
\hline Premix mineral $^{1}$ (Mineral premix) & 0,03 & 0,03 & 0,03 & 0,03 \\
\hline
\end{tabular}

${ }^{1}$ Composição (\%): sulfato de cobre $(22,50)$, sulfato de cobalto $(1,40)$, sulfato de zinco $(75,40)$, iodato de potássio $(0,50)$, selenito de sódio $(0,20)$.

${ }^{1}$ Composition (\%): copper sulfate (22.50), cobalt sulfate (1.40), zinc sulfate (75.40), potassium iodate (0.50), sodium selenite (0.20). 
Tabela 2 - Teores de matéria seca (MS), matéria orgânica (MO), proteína bruta (PB), nitrogênio nãoprotéico (NNP), nitrogênio insolúvel em detergente ácido (NIDA), nitrogênio insolúvel em detergente neutro (NIDN), extrato etéreo (EE), fibra em detergente neutro (FDN), FDN corrigida para cinzas e proteína (FDNcp), carboidratos não-fibrosos (CNF), CNF calculados com a FDNcp (CNFcp), fibra em detergente ácido (FDA) e lignina dos concentrados e do feno, expressos na MS

Table 2 - Contents of dry matter (DM), organic matter (OM), crude protein (CP), nonprotein nitrogen (NPN), acid detergent insoluble nitrogen ( $A D I N)$, neutral detergent insoluble nitrogen (NDIN), ether extract (EE), neutral detergent fiber (NDF), NDF corrected for ash and protein (NDFap), nonfiber carbohydrates (NFC), NFC computed with NDFap (NFCap), acid detergent fiber (ADF), and lignin of the concentrates and hay, expressed in DM basis

\begin{tabular}{|c|c|c|c|c|c|}
\hline \multirow[t]{2}{*}{ Item } & \multicolumn{4}{|c|}{$\begin{array}{l}\text { Concentrado } \\
\text { Concentrate }\end{array}$} & \multirow[t]{2}{*}{$\begin{array}{l}\text { Feno } \\
\text { Hay }\end{array}$} \\
\hline & 1 & 2 & 3 & 4 & \\
\hline $\mathrm{MS}(D M)$ & 90,31 & 90,53 & 90,63 & 90,59 & 86,13 \\
\hline $\mathrm{MO}(\mathrm{OM})$ & 93,70 & 93,63 & 93,59 & 93,23 & 93,36 \\
\hline $\mathrm{PB}(C P)$ & 19,66 & 23,76 & 28,30 & 32,39 & 5,61 \\
\hline $\operatorname{NNP}(N P N)^{1}$ & 38,06 & 33,79 & 32,78 & 32,67 & 31,10 \\
\hline NIDA $(A D I N)^{1}$ & 4,69 & 4,40 & 4,20 & 4,05 & 31,13 \\
\hline NIDN $(N D I N)^{1}$ & 6,98 & 6,87 & 6,02 & 5,52 & 50,81 \\
\hline $\mathrm{EE}$ & 4,06 & 3,79 & 3,53 & 3,28 & 1,12 \\
\hline FDN (NDF) & 12,88 & 13,82 & 14,12 & 15,03 & 84,70 \\
\hline FDNcp (NDFap) & 11,85 & 13,11 & 13,60 & 14,21 & 81,97 \\
\hline $\mathrm{CNF}(N F C)$ & 59,62 & 55,73 & 54,38 & 47,67 & 4,75 \\
\hline CNFcp (NFCap) & 61,76 & 57,45 & 55,74 & 50,12 & 6,58 \\
\hline $\operatorname{FDA}(A D F)$ & 6,48 & 7,90 & 8,36 & 9,99 & 43,30 \\
\hline Lignina (Lignin) & 1,57 & 2,18 & 1,80 & 2,44 & 6,86 \\
\hline
\end{tabular}

$1 \%$ do nitrogênio total (\% of the total nitrogen). 1 - Dieta com 10,5\% de PB (Diet with 10.5\% CP); 2 - Dieta com 12\% de PB (Diet with 12\% CP); 3 - Dieta com 13,5\% de PB (Diet with 13.5\% CP); 4 - Dieta com $15 \%$ de PB (Diet with 15\% CP).

Os teores de compostos nitrogenados nãoprotéicos (NNP), compostos nitrogenados insolúveis em detergente neutro (NIDN) e em detergente ácido (NIDA) foram determinados de acordo com Licitra et al. (1996).

Os carboidratos totais (CHO) foram calculados segundo metodologia da Universidade de Cornell, descrita por Sniffen et al. (1992): \%CHO = $100-$ (\%PB + \%EE + \%cinzas).

Em razão da presença de uréia nas dietas, os carboidratos não-fibrosos (CNF) dos concentrados foram estimados como proposto por Hall (2000), em que $\% C N F=100-[(\% P B-\% P B$ derivada $d a$ uréia + \% de uréia) + \%EE + \%FDN + \%cinzas].
Tabela 3 - Teores de matéria seca (MS), matéria orgânica (MO), proteína bruta (PB), nitrogênio nãoprotéico (NNP), nitrogênio insolúvel em detergente ácido (NIDA), nitrogênio insolúvel em detergente neutro (NIDN), extrato etéreo (EE), fibra em detergente neutro (FDN), FDN corrigida para cinzas e proteína (FDNcp), carboidratos não-fibrosos (CNF), CNF calculados com a FDNcp (CNFcp), fibra em detergente ácido (FDA), lignina e nutrientes digestíveis totais (NDT) das dietas, expressos na MS

Table 3 - Contents of dry matter (DM), organic matter (OM), crude protein $(C P)$, nonprotein nitrogen (NPN), acid detergent insoluble nitrogen (ADIN), neutral detergent insoluble nitrogen (NDIN), ether extract $(E E)$, neutral detergent fiber (NDF), NDF corrected for ash and protein (NDFap), nonfiber carbohydrate (NFC), NFC computed with NDFap (NFCap), acid detergent fiber (ADF), lignin, and total digestible nutrients (TDN) of the diets, expressed in DM basis

\begin{tabular}{lrrrr}
\hline Item & \multicolumn{4}{c}{ Nível de PB (\%) } \\
& \multicolumn{4}{c}{ CP level (\%) } \\
\cline { 2 - 5 } & 10,5 & \multicolumn{1}{c}{12} & 13,5 & \multicolumn{1}{c}{15} \\
\hline MS (DM) & 87,59 & 87,67 & 87,71 & 87,69 \\
MO (OM) & 93,48 & 93,45 & 93,44 & 93,31 \\
PB (CP) & 10,53 & 11,96 & 13,55 & 14,98 \\
NNP (NPN) & 33,54 & 32,04 & 31,69 & 31,65 \\
NIDA (ADIN) & 21,88 & 21,77 & 21,70 & 21,65 \\
NIDN (NDIN) & 35,47 & 35,43 & 35,13 & 34,96 \\
EE & 2,15 & 2,05 & 1,96 & 1,88 \\
FDN (NDF) & 59,56 & 59,89 & 60,00 & 60,32 \\
FDNcp (NDFap) & 57,43 & 57,87 & 58,22 & 58,25 \\
CNF (NFC) & 23,95 & 22,59 & 22,12 & 19,77 \\
CNFcp (NFCap) & 25,89 & 24,38 & 23,79 & 21,82 \\
FDA (ADF) & 30,41 & 30,91 & 31,07 & 31,64 \\
Lignina (Lignin) & 5,01 & 5,22 & 5,09 & 5,31 \\
NDT (TDN) & 63,65 & 63,88 & 63,09 & 63,82 \\
\hline
\end{tabular}

1\% do nitrogênio total (\% of the total nitrogen).

Os teores de nutrientes digestíveis totais (NDT) foram determinados pela equação de Weiss (1999): $N D T=P B_{d}+2,25 E E_{d}+F D N_{d}+C N F_{d}$, em que $P B_{d}$ é $\mathrm{PB}$ digestível, $E E_{d}$; o $\mathrm{EE}$ digestível; $F D N_{d}$, a FDN digestível; e $C N F_{d}$, os CNF digestíveis.

Os dados obtidos foram submetidos às análises de variância e de regressão, utilizando-se o Sistema de Análises Estatísticas e Genéticas - SAEG (UFV, 1995). Os modelos foram escolhidos adotando-se como critério a significância observada entre tratamentos pelo teste $\mathrm{F}$, a $5 \%$ de probabilidade, e o coeficiente de determinação $\left(\mathrm{r}^{2}\right)$ foi calculado como a relação entre a soma de quadrados da regressão e a soma de quadrados de tratamentos. 


\section{Resultados e Discussão}

As médias, as equações de regressão e os respectivos coeficientes de determinação dos consumos diários dos nutrientes, de acordo com os níveis de PB das dietas, são apresentados na Tabela 4. Os consumos diários de MS, FDN, FDN corrigida para cinzas e proteína (FDNcp) e NDT, expressos em kg/dia e em porcentagem do peso vivo (PV), não foram influenciados $(\mathrm{P}>0,05)$ pelos níveis de $\mathrm{PB}$ das dietas.

A exemplo dos nutrientes descritos anteriormente, o consumo de MO, expresso em kg/dia, também não foi afetado pelas dietas, observando-se valor médio de 7,24 . De acordo com Van Soest (1994), concentrações de PB acima de 7\% não influenciam o consumo, porém provocam declínio na ingestão de MS nas dietas com menos de $7 \%$ de PB na matéria seca. Valadares et al. (1997a) que, ao avaliarem dietas contendo 7; 9,5; 12 e 14,5\% de PB na MS, observaram consumo de MS da dieta contendo 7\% de PB inferior ao dos demais níveis, que não diferiram entre si.
Os consumos médios diários de MS obtidos neste trabalho para as dietas com 10,5; 12; 13,5 e 15\% de PB foram, respectivamente, 7,59; 7,86; 7,45 e 7,87 kg. Esses valores podem ser considerados baixos, o que pode ser explicado, em parte, pelo tamanho dos animais (487,3 kg $\pm 54,5$ de peso vivo inicial) utilizados neste experimento. A composição corporal, especialmente a porcentagem de gordura corporal, pode afetar a ingestão de alimentos, sobretudo quando o animal se aproxima da maturidade, uma vez que maior proporção de gordura é depositada. Em geral, para qualquer tamanho corporal, existe uma relação linear decrescente entre a quantidade de gordura do animal e o consumo de alimentos, conforme verificado por Silva et al. (2002), que obteve a seguinte equação: $\hat{\mathrm{Y}}=3,1237-0,0028 * \mathrm{PV}\left(\mathrm{r}^{2}=0,21\right)$, em que $\hat{\mathrm{Y}}$ é o consumo de MS, em \% do PV, estimado em função do peso vivo, em kg. Outra explicação é o efeito feedback do tecido adiposo no controle do consumo, pois, segundo o NRC (1987), para um novilho de porte médio, o consumo por unidade de peso metabólico começa a declinar a partir de $350 \mathrm{~kg}$.

Tabela 4 - Médias, equações de regressão (ER) e coeficientes de determinação ( $r^{2}$ ) e variação (CV) obtidos para os consumos diários de matéria seca (MS), matéria orgânica (MO), proteína bruta (PB), extrato etéreo (EE), fibra em detergente neutro (FDN), FDN corrigida para cinzas e proteína (FDNcp), carboidratos não-fibrosos (CNF), CNF calculados com a FDNcp (CNFcp) e nutrientes digestíveis totais (NDT), de acordo com os níveis de proteína bruta das dietas

Table 4 - Means, regression equations (RE), and coefficients of determination $\left(r^{2}\right)$ and variation (CV) for the daily intakes of dry matter $(D M)$, organic matter $(O M)$, crude protein $(C P)$, ether extract (EE), neutral detergent fiber (NDF), NDF corrected for ash and protein (NDFap), nonfiber carbohydrates (NFC), NFC computed with NDFap (NFCap), and total digestible nutrients (TDN), in response to different dietary crude protein levels

\begin{tabular}{|c|c|c|c|c|c|c|}
\hline \multirow[t]{2}{*}{ Item } & \multicolumn{4}{|c|}{$\begin{array}{c}\text { Nível de PB (\%) } \\
\text { CP level (\%) }\end{array}$} & \multirow[t]{2}{*}{$\begin{array}{l}\mathrm{ER} \\
\mathrm{RE}\end{array}$} & \multirow[t]{2}{*}{$\mathrm{CV}$} \\
\hline & 10,5 & 12 & 13,5 & 15 & & \\
\hline \multicolumn{7}{|c|}{ kg/dia (kg/day) } \\
\hline MS (DM) & 7,59 & 7,86 & 7,45 & 7,87 & $\hat{\mathrm{Y}}=7,69$ & 12,38 \\
\hline $\mathrm{MO}(\mathrm{OM})$ & 7,18 & 7,41 & 6,99 & 7,36 & $\hat{Y}=7,24$ & 10,58 \\
\hline $\mathrm{PB}(C P)$ & 0,82 & 0,99 & 1,04 & 1,22 & ${ }^{1} \hat{Y}$ & 8,93 \\
\hline $\mathrm{EE}(E E)$ & 0,208 & 0,183 & 0,148 & 0,145 & ${ }^{2} \hat{Y}$ & 21,72 \\
\hline FDN (NDF) & 4,39 & 4,54 & 4,39 & 4,74 & $\hat{Y}=4,52$ & 13,47 \\
\hline FDNcp (NDFap) & 4,19 & 4,34 & 4,22 & 4,53 & $\hat{Y}=4,32$ & 13,85 \\
\hline $\mathrm{CNF}(N F C)$ & 1,86 & 1,82 & 1,55 & 1,42 & ${ }^{3 \hat{Y}}$ & 6,18 \\
\hline CNFcp (NFCap) & 2,06 & 2,01 & 1,72 & 1,64 & ${ }^{4} \hat{Y}$ & 6,12 \\
\hline NDT $(T D N)$ & 4,73 & 5,23 & 4,81 & 5,72 & $\hat{\mathrm{Y}}=5,12$ & 16,25 \\
\hline \multicolumn{7}{|c|}{ \% PV (BW\%) } \\
\hline MS (DM) & 1,49 & 1,56 & 1,48 & 1,52 & $\hat{Y}=1,51$ & 12,45 \\
\hline FDN (NDF) & 0,86 & 0,90 & 0,87 & 0,91 & $\hat{\mathrm{Y}}=0,89$ & 15,05 \\
\hline FDNcp (NDFap) & 0,82 & 0,86 & 0,84 & 0,87 & $\hat{Y}=0,85$ & 15,35 \\
\hline NDT $(T D N)$ & 0,93 & 1,04 & 0,95 & 1,10 & $\hat{Y}=1,02$ & 17,36 \\
\hline
\end{tabular}

* Significativo a $5 \%$ de probabilidade pelo teste $\mathrm{F}$ (Significant at probability of $5 \%$ by $\mathrm{F}$ test).

$1 \hat{Y}=-0,03786+0,0827^{\star} P B\left(r^{2}=0,91\right) ;{ }^{2} \hat{Y}=0,35942-0,00147^{*} P B\left(r^{2}=0,91\right) ; 3 \hat{Y}=2,99025-0,10433^{*} P B\left(r^{2}=0,93\right) ;$

$4 \hat{\mathrm{Y}}=3,1775-0,10333^{*} \mathrm{~PB}\left(\mathrm{r}^{2}=0,87\right)$. 
Os consumos de FDN, calculados de ambas as formas, com e sem correção para cinzas e proteína nos alimentos, cujas médias variaram de 0,82 a 0,87\% do PV e de 0,86 a 0,91\% do PV (Tabela 4), respectivamente, foi inferior ao valor de $1,2 \%$ do PV preconizado por Mertens (1992), em que ocorre o consumo de MS para o desempenho ótimo em vacas leiteiras. A ausência de efeito dos níveis de proteína bruta das dietas sobre o consumo de FDN pode ser atribuída à ausência de efeito das dietas sobre o consumo de MS, uma vez que seus teores de FDN foram relativamente próximos.

Ausência de efeito do teor de PB das dietas sobre o consumo de MS, MO e FDN em novilhos Nelore também foi observada Ítavo et al. (2002), utilizando dietas com 15 e $18 \%$ de PB. Outros autores, contudo, observaram efeito do nitrogênio dietético sobre os consumos de MS e MO, entre eles, Dias et al. (2000), em novilhos $F_{1}$ Limousin $x$ Nelore, com peso vivo médio inicial de $268 \mathrm{~kg}$, submetidos a dietas contendo teores de PB de 10,62 a 15,50\% na MS, e Silva et al. (2002), em novilhos Nelore, na fase de engorda, consumindo dietas com teores de PB de 15 e $18 \%$ na MS. As diferenças registradas pelos diferentes autores para essas variavéis podem ser atribuídas a variações relacionadas aos níveis protéicos utilizados, às raças, ao nível energético das dietas e à idade dos animais.

$\mathrm{O}$ consumo de $\mathrm{PB}$, em kg/dia, aumentou linearmente $(\mathrm{P}<0,05)$ com o incremento de $\mathrm{PB}$ das dietas, registrando-se acréscimo de 0,08 unidades para cada percentual de aumento na PB das dietas, provavelmente em razão do aumento do teor de proteína bruta das dietas, uma vez que o consumo de matéria seca não variou entre as dietas. Ítavo et al. (2002), avaliando o consumo de novilhos zebuínos na fase de recria, submetidos a dietas com 15 e $18 \%$ de PB, verificaram que apenas o consumo de PB foi afetado pelas dietas. Resultado semelhante foi obtido por Rennó (2003), ao avaliar duas dietas com dois níveis de PB (12 e 15\% na MS) para animais Holandês, 1/2Holandês-Guzerá, 1⁄2Holandês-Gir e Zebu.

Os consumos de EE e CNF, expresso em $\mathrm{kg} /$ dia, decresceram de forma linear $(\mathrm{P}<0,05)$ com o aumento do teor de $\mathrm{PB}$ nas dietas, o pode ser atribuído à redução do teor de EE, com o aumento da $\mathrm{PB}$, resultante da menor proporção de milho nas dietas.

Considerando-se que o consumo de NDT é obtido por adição, a ausência de efeito do aumento de PB das dietas pode estar relacionada à forma como esse efeito é calculado, pois o efeito positivo do teor de PB das dietas sobre o consumo de $\mathrm{PB}$ digestível, neste caso, foi anulado pelo efeito negativo sobre os consumos de EE digestível e dos CNF digestíveis. Além disso, como os teores de NDT das dietas foram ligeiramente semelhantes e não se verificou diferença para o consumo de MS, esperava-se que o consumo de NDT também não fosse afetado pelo incremento protéico das dietas.

As médias, as equações de regressão e os respectivos coeficientes de determinação e variação obtidos para os coeficientes de digestibilidade total dos nutrientes, de acordo com os níveis de proteína bruta das dietas, encontram-se na Tabela 5. As digestibilidades aparentes totais da MS, MO e PB aumentaram linearmente $(\mathrm{P}<0,05)$ com o incremento dos níveis de proteína bruta nas dietas. Para as digestibilidades da MS e MO, estimaram-se acréscimos de aproximadamente 2,24 e 2,18 unidades por unidade percentual de PB das dietas, respectivamente. Resultados semelhantes também foram observados por Valadares et al. (1997a), que registraram incrementos de 1,17 e 1,09 unidades nos coeficientes de digestibilidades aparentes dos respectivos nutrientes, em novilhos Zebu.

Estimaram-se incrementos na digestibilidade aparente total da $\mathrm{PB}$ de 3,14 unidades por unidade de acréscimo no nível de proteína bruta das dietas (Tabela 5). Rennó (2003) observou que a digestibilidade total da PB também foi influenciada pela concentração protéica das dietas (12 e 15\%), cujos valores médios foram de 71,48 e 74,57\%, respectivamente. Resultados similares foram encontrados por Valadares et al. (1997a), que atribuíram o fato à progressiva diminuição da proporção de nitrogênio endógeno nos compostos nitrogenados fecais, com o aumento da ingestão de compostos nitrogenados.

As digestibilidades totais de EE, FDN e CNF não diferiram $(\mathrm{P}>0,05)$ entre as dietas e apresentaram médias de 77,97; 56,61 e 89,21\%, respectivamente.

A ausência de efeito dos níveis protéicos sobre a digestibilidade aparente total da FDN pode ser explicada pela síntese de proteína microbiana, que, segundo Cavalcante (2004), não foi afetada pelas dietas. Neste caso, não houve melhoria do aproveitamento dessa fração decorrente do provável aumento na fermentação microbiana, favorecida pelos mais altos níveis de PB. Rennó (2003) também não encontrou efeito dos níveis de proteína bruta das dietas sobre as digestibilidades totais de FDN e CNF, cujos valores médios foram, respectivamente, de 65,19 e 86,69\%. 
Entretanto, Valadares et al. (1997a) observaram diferença nos coeficientes de digestibilidades aparentes totais da FDN somente para os níveis de 7 e 14,5\% de PB das dietas, não se verificando diferença nos níveis intermediários (9,5 e 12\%).

As médias, as equações de regressão e os respectivos coeficientes de determinação e variação das digestibilidades ruminal e intestinal dos nutrientes, de acordo com os níveis de proteína bruta das dietas, encontram-se na Tabela 6. Os coeficientes de digestibilidade ruminal de todos os nutrientes não foram afetados $(\mathrm{P}>0,05)$ pelos níveis de proteína bruta das dietas.

Ausência de efeito de níveis crescentes de proteína bruta sobre os coeficientes de digestibilidades ruminais da MS, MO e FDN foi observada por Valadares et al. (1997a). Rennó (2003) verificou que as digestões ruminais dos nutrientes não foram afetadas pelos níveis de PB das dietas, com exceção do EE e da FDN, que apresentaram comportamentos lineares negativo e positivo, respectivamente.

Neste trabalho, a ausência de efeito dos níveis de PB das dietas sobre a digestibilidade ruminal do EE, que variou de 8,55 a $-3,52 \%$, para os níveis de 10,5 e $15 \%$ de $\mathrm{PB}$, respectivamente, pode ser explicada pelo alto coeficiente de variação $(749,82 \%)$. Os valores negativos para a digestibilidade ruminal do EE nas dietas contendo 13,5 e 15\% de PB indicam que houve síntese de lipídios microbianos, provavel- mente em decorrência dos baixos teores de EE apresentados por essas dietas (1,96 e 1,88\%, respectivamente). O fato de a digestão ruminal da FDN não ter sido influenciada pelos níveis de $\mathrm{PB}$ das dietas (Tabela 6) pode estar relacionado ao crescimento microbiano, que também não foi afetado; ou seja, a dieta com menor teor de PB (10,5\%) provavelmente forneceu compostos nitrogenados suficientes para ótimo crescimento microbiano.

As digestibilidades intestinais da MS, MO, EE, FDN e CNF não foram influenciadas $(\mathrm{P}>0,05)$ pelos níveis de $\mathrm{PB}$ das dietas, apresentando valores médios de 38,67; 28,29; 78,2; 12,23 e 27,46\%, respectivamente. A digestibilidade intestinal total da $\mathrm{PB}$, no entanto, aumentou linearmente com a adição de PB nas dietas ( $\mathrm{P}<0,05)$, possivelmente em razão do teor de proteína verdadeira, proporcionado pela adição de farelo de algodão nas dietas.

Rennó (2003) verificou que, à exceção da FDN, todas as digestibilidades intestinais não foram influenciadas pelo incremento de PB na dieta. Valadares et al. (1997a), avaliando dietas com 7; 9,5; 12 e $14,5 \%$ de $\mathrm{PB}$, relataram que as digestibilidades intestinais da MS, MO e do EE não foram afetadas pelas dietas.

Analisando-se a digestão em todo o trato gastrintestinal, observou-se que, em média, 87,78\% da FDN e $81,82 \%$ dos carboidratos totais foram digeridos no rúmen.

Tabela 5 - Médias, equações de regressão (ER) e coeficientes de determinação ( $r^{2}$ ) e variação (CV) obtidos para as digestibilidades totais de matéria seca (MS), matéria orgânica (MO), proteína bruta (PB), extrato etéreo (EE), fibra em detergente neutro (FDN) e carboidratos não-fibrosos (CNF), de acordo com os níveis de proteína bruta das dietas

Table 5 - Means, regression equations (RE), and coefficients of determination $\left(r^{2}\right)$ and variation (VC) for the apparent total tract digestibilities of dry matter (DM), organic matter (OM), crude protein (CP), ether extract (EE), neutral detergent fiber (NDF), and nonfiber carbohydrates (NFC), in response to different dietary crude protein levels

\begin{tabular}{|c|c|c|c|c|c|c|}
\hline \multirow[t]{2}{*}{ Item } & \multicolumn{4}{|c|}{$\begin{array}{c}\text { Nível de PB (\%) } \\
\text { CP level (\%) }\end{array}$} & \multirow[t]{2}{*}{$\begin{array}{l}\mathrm{ER} \\
R E\end{array}$} & \multirow[t]{2}{*}{ CV } \\
\hline & 10,5 & 12 & 13,5 & 15 & & \\
\hline MS (DM) & 60,39 & 65,22 & 63,33 & 72,22 & ${ }^{1} \hat{Y}$ & 5,55 \\
\hline MO (OM) & 61,42 & 66,59 & 64,35 & 73,06 & ${ }^{2} \hat{Y}$ & 5,67 \\
\hline $\mathrm{PB}(C P)$ & 65,52 & 73,56 & 73,28 & 81,34 & ${ }^{3} \hat{Y}$ & 4,12 \\
\hline $\mathrm{EE}(E E)$ & 80,89 & 75,43 & 76,80 & 78,77 & $\hat{Y}=77,97$ & 7,21 \\
\hline FDN (NDF) & 50,62 & 56,24 & 53,82 & 65,77 & $\hat{Y}=56,61$ & 10,72 \\
\hline CNF (NFC) & 84,44 & 89,58 & 90,01 & 92,80 & $\hat{Y}=89,21$ & 4,64 \\
\hline
\end{tabular}

* Significativo a $5 \%$ de probabilidade pelo teste $\mathrm{F}$ (Significant at $5 \%$ by $\mathrm{F}$ test).

$1 \hat{Y}=36,7417+2,23905^{*} P B\left(r^{2}=0,74\right) ;{ }^{2} \hat{Y}=38,5769+2,17854^{*} P B\left(r^{2}=0,73\right) ;{ }^{3} \hat{Y}=33,3601+3,14234^{*} P B\left(r^{2}=0,89\right)$ 
Tabela 6 - Médias, equações de regressão (ER) e coeficientes de determinação ( $r^{2}$ ) e variação (CV) obtidos para as digestibilidades ruminais e intestinais da matéria seca (MS), matéria orgânica (MO), proteína bruta (PB), extrato etéreo (EE), fibra em detergente neutro (FDN) e carboidratos não-fibrosos (CNF), de acordo com os níveis de proteína bruta das dietas

Table 6 - Means, regression equations (RE), and coefficients of determination $\left(r^{2}\right)$ and variation (CV) for the ruminal and intestinal digestibilities of dry matter (DM), organic matter (OM), crude protein (CP), ether extract (EE), neutral detergent fiber (NDF), and nonfiber carbohydrate (NFC), in response to different dietary crude protein levels

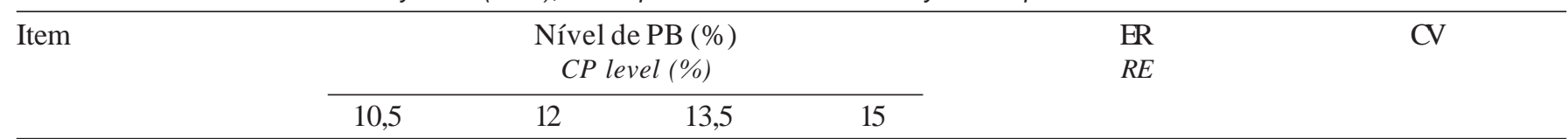

Digestibilidade ruminal (Ruminal digestibility)

\begin{tabular}{|c|c|c|c|c|c|c|}
\hline $\mathrm{MS}^{1}$ & 60,89 & 62,28 & 60,62 & 61,52 & $\hat{Y}=61,33$ & 3,63 \\
\hline $\mathrm{MO}^{1}$ & 71,40 & 72,19 & 72,36 & 70,88 & $\hat{\mathrm{Y}}=71,71$ & 8,31 \\
\hline $\mathrm{PB}^{2}$ & 14,86 & 22,93 & 25,15 & 29,59 & $\hat{\mathrm{Y}}=23,13$ & 25,09 \\
\hline $\mathrm{EE}^{2}$ & 8,55 & 5,74 & $-1,79$ & $-3,52$ & $\hat{Y}=2,25$ & 749,82 \\
\hline $\mathrm{FDN}^{1}$ & 85,15 & 88,32 & 88,79 & 88,84 & $\hat{Y}=87,78$ & 9,90 \\
\hline $\mathrm{CNF}^{1}$ & 77,99 & 73,39 & 74,32 & 64,46 & $\hat{\mathrm{Y}}=72,54$ & 25,41 \\
\hline
\end{tabular}

Digestibilidade intestinal (Intestinal digestibility)

\begin{tabular}{|c|c|c|c|c|c|c|}
\hline $\mathrm{MS}^{1}$ & 39,11 & 37,73 & 39,38 & 38,48 & $\hat{Y}=38,67$ & 5,76 \\
\hline $\mathrm{MO}^{1}$ & 28,60 & 27,81 & 27,64 & 29,12 & $\hat{\mathrm{Y}}=28,29$ & 21,07 \\
\hline $\mathrm{PB}^{2}$ & 59,38 & 65,20 & 64,27 & 73,52 & $\hat{\mathrm{Y}}^{3}$ & 7,23 \\
\hline $\mathrm{EE}^{2}$ & 79,82 & 73,49 & 76,52 & 82,96 & $\hat{Y}=78,20$ & 8,50 \\
\hline $\mathrm{FDN}^{1}$ & 14,85 & 11,68 & 11,21 & 11,16 & $\hat{\mathrm{Y}}=12,23$ & 71,09 \\
\hline $\mathrm{CNF}^{1}$ & 22,01 & 26,61 & 25,68 & 35,54 & $\hat{\mathrm{Y}}=27,46$ & 65,61 \\
\hline
\end{tabular}

* Significativo a $5 \%$ de probabilidade pelo teste $\mathrm{F}$ (Significant at probability of $5 \%$ by $\mathrm{F}$ test).

1 Digestibilidade calculada em \% do total digestível (Digestibility calculated as \% of total digestion).

2 Digestibilidade calculada em \% da quantidade que chegou em cada local (Digestibility calculated as \% of the amount that reached each compartment).

$3 \hat{Y}=30,3318+2,7655^{\star} P B\left(r^{2}=0,83\right)$.

\section{Conclusões}

A adição de níveis crescentes de proteína bruta às dietas não alterou os consumos de matéria seca, fibra em detergente neutro e nutrientes digestíveis totais, mas resultou em maiores coeficientes de digestibilidade aparente total de MS e PB, sem alterar a digestibilidade ruminal dos nutrientes avaliados.

\section{Literatura Citada}

ALVES, D.D. Desempenho produtivo e características de carcaças de bovinos zebu e cruzados Holandês-zebu ( $\left.F_{1}\right)$, nas fases de recria e terminação. Viçosa, MG: Universidade Federal de Viçosa, 2001. 77p. Dissertação (Mestrado em Zootecnia) - Universidade Federal de Viçosa, 2001.

CAVALCANTE, M.A.B. Níveis de proteína bruta em dietas de bovinos de corte: consumo, digestibilidade, produção microbiana, parâmetros ruminais e desempenho produtivo. Viçosa, MG: Universidade Federal de Viçosa, 2004. 58p. Tese (Doutorado em Zootecnia) - Universidade Federal de Viçosa, 2004.

DIAS, H.L.C.; VALADARES FILHO, S.C.; SILVA, J.F.C. et al. Consumo e digestões totais e parciais em novilhos F1 Limousin $\mathrm{x}$ Nelore alimentados com dietas contendo cinco níveis de concentrado. Revista Brasileira de Zootecnia, v.29, n.2, p.545-554, 2000.
HALL, M.B. Calculation of non-structural carbohydrate content of feeds that contain non-protein nitrogen. University of Florida. 2000. p.A-25 (Bulletin 339).

ÍTAVO, L.C.V.; VALADARES FILHO, S.C.; SILVA, F.F. et al. Níveis de concentrado e proteína bruta na dieta de bovinos Nelore nas fases de recria e terminação: consumo e digestibilidade. Revista Brasileira de Zootecnia, v.31, n.2, p.1033-1041, 2002. (Supl.)

LICITRA, G.; HERNANDEZ, T.M.; Van SOEST, P.J. Standardization of procedures for nitrogen fractionation of ruminant feeds. Animal Feed Science and Technology, v.57, n.4, p.347-358, 1996.

MERTENS, D.R. Análise de fibra e sua utilização na avaliação e formulação de rações. In: SIMPÓSIO INTERNACIONAL DE RUMINANTES. REUNIÃO ANUAL DA SOCIEDADE BRASILEIRA DE ZOOTECNIA, 29., 1992, Lavras. Anais... Lavras: Sociedade Brasileira de Zootecnia, 1992. p.188.

MERTENS, D.R. Regulation of forage intake. In: FAHEY Jr, G.C. (Ed.) Forage quality, evaluation and utilization. Madison: American Society of Agronomy, 1994. p.450-493.

MERTENS, D.R.; ELY, L.O. A dynamic model of fiber digestion and passage in the ruminant for evaluating forage quality. Journal of Animal Science, v.49, n.4, p.1085-1095, 1979.

NATIONAL RESEARCH COUNCIL - NRC. Nutrients requirements of beef cattle. 6.ed. Washington, D.C.: National Academy Press, 1984. 90p.

NATIONAL RESEARCH COUNCIL - NRC. Predicting feed intake of food-producing animals. Washington, D.C.: National Academy Press, 1987. 85p. 
NATIONAL RESEARCH COUNCIL - NRC. Nutrients requirements of dairy cattle. 6.ed. Washington, D.C.: National Academy Press, 1989. 159p.

PELL, A.N.; SCHOFIELD, P. Computerized monitoring of gas production to measure forage digestion in vitro. Journal of Dairy Science, v.76, n.10, p.1063-1073, 1993.

RENNÓ, L.N. Consumo, digestibilidade total e parcial, produção microbiana, parâmetros ruminais e excreções de uréia e creatinina em novilhos alimentados com dietas contendo quatro níveis de uréia ou dois níveis de proteína. Viçosa, MG: Universidade Federal de Viçosa, 2003. 252p. Tese (Doutorado em Zootecnia) - Universidade Federal de Viçosa, 2003.

SILVA, D.J.; QUEIROZ, A.C. Análise de alimentos: métodos químicos e biológicos. 3.ed. Viçosa, MG: Universidade Federal de Viçosa, 2002. 235p.

SILVA, F.F.; VALADARES FILHO, S.C.; ÍTAVO, L.C.V. et al. Desempenho produtivo de novilhos nelores, na recria e na engorda, recebendo dietas com diferentes níveis de concentrado e proteína. Revista Brasileira de Zootecnia, v.31, n.1, p.492-502, 2002 (Supl.)

SNIFFEN, C.J.; O’CONNOR, J.D.; Van SOEST, P.J. et al. A net carbohydrate and protein system for evaluating cattle diets: II. Carbohydrate and protein availability. Journal of Animal Science, v.70, n.11, p.3562-3577, 1992.

UNIVERSIDADE FEDERAL DE VIÇOSA - UFV. SAEG Sistema de análises estatísticas e genéticas. Versão 8.0. Viçosa, MG, 1998. (Manual do usuário).

VALADARES FILHO, S.C.; VALADARES, R.F.D. Recentes avanços em proteína na nutrição de vacas leiteiras. In: SIMPÓSIO INTERNACIONAL DE BOVINOCULTURA DE LEITE, SINLEITE, 2., 2001, Lavras. Anais... Lavras: Universidade Federal de Lavras, 2001. p.228-243.
VALADARES, R.F.D.; GONÇALVES, L.C.; RODRIGUEZ, N.M. et al. Níveis de proteína em dietas de bovinos. 1. Consumo e digestibilidades aparentes totais e parciais. Revista Brasileira de Zootecnia, v.26, n.6, p.1252-1258, 1997a.

VALADARES, R.F.D.; GONÇALVES, L.C.; SAMPAIO, I.B. et al. Níveis de proteína bruta em dietas de bovinos. 2. Consumo, digestibilidades e balanço de compostos nitrogenados. Revista Brasileira de Zootecnia, v.26, n.6, p.1259-1263, 1997b.

Van SOEST, P.J. Nutritional ecology of the ruminants. 2.ed. Ithaca: Cornell University, 1994. 476p.

WALDO, D.R.; JORGENSEN, N.S. Forages for high animal production: nutritional factors and effects of conservation. Journal of Dairy Science, v.64, n.6, p.1207-1229, 1981.

WEISS, W.P. Energy prediction equations for ruminant feeds. In: CORNELL NUTRITION CONFERENCE FOR FEED MANUFACTUREs, 61., 1999, Ithaca. Proceedings... Ithaca: Cornell University, 1999. p.176-185.

WILLIAMS, C.H.; DAVID, D.J.; IISMA, O. The determination of chromic oxide in faeces samples by atomic absorption spectrophotometry. Journal of Agriculture Science, v.59, p.381-385, 1962. 